\title{
miR-185-5p targets ROCK2 and inhibits cell migration and invasion of hepatocellular carcinoma
}

\author{
YUEXIANG NIU and GONGEN TANG \\ Department of Infectious Diseases, Linyi Central Hospital, Linyi, Shandong 276400, P.R. China
}

Received March 7, 2018; Accepted March 1, 2019

DOI: 10.3892/ol.2019.10144

\begin{abstract}
Previous studies demonstrated microRNA-185 (miR-185) as a tumor suppressive microRNA (miRNA) in various types of cancer. The current study aimed to verify this finding in hepatocellular carcinoma (HCC) and explored the downstream channel of miR-185-5p. We detected miR-185-5p and Rho-associated coiled-coil containing protein kinase 2 (ROCK2) mRNA and protein levels by reverse transcription-quantitative PCR (RT-qPCR) and western blotting in HCC tissues and cell lines. Luciferase reporter assay proved the direct relationship between miR-185-5p and ROCK2. Cell migration and invasion were assessed via Transwell assay. miR-185-5p level was reduced in HCC tissues and cell lines. miR-185-5p overexpression impeded migration and invasion of HCC cells. Moreover, miR-185-5p directly targeted ROCK2 which was repressed by miR-185-5p in HCC. In addition, ROCK 2 contributed to cell metastasis of HCC. In summary, miR-185-5p inhibited cell metastasis of HCC by suppressing ROCK2. The novel miR-185/ROCK2 axis shows potential in improving the therapies of HCC and enhancing HCC survival.
\end{abstract}

\section{Introduction}

Hepatocellular carcinoma (HCC) can be divided into two major categories: primary and secondary liver cancer. Especially, primary HCC is a highly harmful malignant tumor worldwide (1). The etiology and exact molecular mechanism of primary $\mathrm{HCC}$ is not fully understood. It is reported that its pathogenesis is a complex multistep process, which is controlled by environmental and genetic factors (2). However, the 5-year survival rate of $\mathrm{HCC}$ remains low at $10 \%$ because of poor diagnosis and prognosis (3). A beneficial treatment for patients suffering from HCC has not been achieved although hepatic resection and liver transplantation therapies have

Correspondence to: Dr Yuexiang Niu, Department of Infectious Diseases, Linyi Central Hospital, 81 Yimeng Road, Yishui, Linyi, Shandong 276400, P.R. China

E-mail: nwm65m@163.com

Key words: hepatocellular carcinoma, miR-185-5p, migration, invasion, Rho-associated coiled-coil containing protein kinase 2 improved in recent years (4). Therefore, it is still necessary to investigate regulatory pathways of HCC progression.

MicroRNA (miRNA) can reversely control gene expression by degrading mRNA and repressing translation although it cannot encode proteins (5). Research has identified that miRNA dysregulation influenced the initiation and development of various cancer types, including HCC. For instance, miR-448 was downregulated and promoted invasion by inhibiting Rho-associated coiled-coil containing protein kinase 2 (ROCK2) in HCC (6). Chen et al demonstrated that miR-490-5p inhibited HCC proliferation and metastasis by affecting ROBO1 (7). In addition, miR-96, miR-758-3p and miR-1260b were found to regulate HCC formation (8-10). Among them, microRNA-185 (miR-185) was connected with various human cancers such as breast cancer (11), non-small cell lung cancer (12), glioma (13) and colorectal cancer (14). However, the role of miR-185 in tumorigenesis of HCC remains to be elucidated.

ROCK 2 belonging to the family of serine/threonine kinases has been identified to affect tumor development. ROCK2 was reported to play a carcinogenic role in lung and breast cancers $(15,16)$. Moreover, RhoE/ROCK2 affects chemoresistance through NF- $\kappa \mathrm{B} / \mathrm{IL}-6 / \mathrm{STAT} 3$ signaling in HCC (17). ROCK 2 promoted HCC proliferation by suppressing CEBPD through phospho-GSK3 $\beta / \beta$-catenin signaling (18). However, the function of miR-185-5p/ROCK2 in HCC remains to be determined.

In the current study, we paid attention to miR-185-5p and its association with ROCK2 in HCC. Importantly, these findings could supplement the regulatory pathway of miR-185-5p in HCC.

\section{Materials and methods}

Clinical tissue samples. Fifty-four surgical tumor specimens and adjacent tissue samples were obtained from the Linyi Central Hospital (Linyi, China). None of the patients received treatment before surgery, and all the participants signed informed consent. Human tissue was frozen in liquid nitrogen and then stored at $-80^{\circ} \mathrm{C}$ refrigerator for further use. All the tissue samples of the experiment were approved by the Linyi Central Hospital Institutional Ethics Committee.

Cell culture and transfection. The human HCC cell lines Hep-3B and SNU-387, a normal liver cell line (LO-2) were 
A

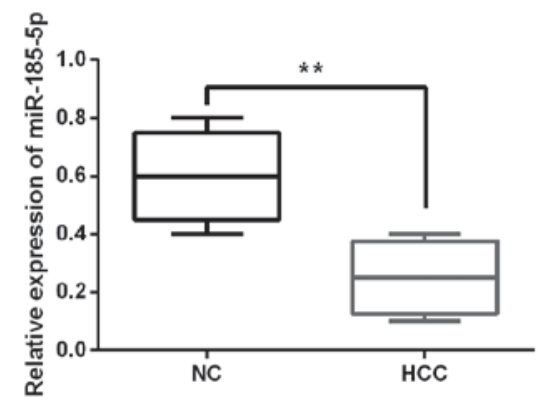

B

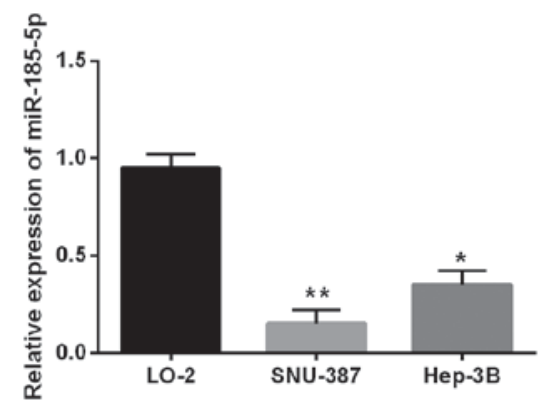

Figure 1. miR-185-5p levels are decreased in HCC. (A) The miR-185-5p expression was downregulated in tumor tissues. (B) The miR-185-5p expression in HepG2, SNU-387 and LO-2 (control). ${ }^{*} \mathrm{P}<0.05,{ }^{* *} \mathrm{P}<0.01$. HCC, hepatocellular carcinoma.

used in this study. All the cell lines were obtained from the American Type Culture Collection (ATCC, Manassas, VA, USA), and were cultured in DMEM containing $10 \%$ fetal bovine serum (FBS). These cells were grown in an incubator at $37^{\circ} \mathrm{C}$, with $5 \% \mathrm{CO}_{2}$ atmosphere. The medium was replaced every other day according to the culture state.

The miR-185-5p mimic and inhibitor, ROCK2 siRNA were purchased from Guangzhou RiboBio Co., Ltd. (Guangzhou, China) and were transferred into SNU-387 cells with Lipofectamine 2000 (Invitrogen; Thermo Fisher Scientific, Inc., Carlsbad, CA, USA) according to the manufacturer's protocols.

$R N A$ extraction and reverse-transcription quantitative $P C R$ ( $R T-q P C R$ ). TRIzol reagent (Invitrogen; Thermo Fisher Scientific, Inc.) was used to extract total RNA containing miRNA to quantify miR-185-5p expression in HCC tissues and cell lines. RT-qPCR was carried out using the QuantiTect SYBR-Green PCR mixture on an ABI7900 LightCycler (Roche Diagnostics, Basel, Switzerland). U6 and GAPDH served as the control of miR-185-5p and ROCK2. The miR-185-5p and ROCK2 levels were analyzed using the $2^{-\Delta \Delta \mathrm{Cq}}$ method (19).

Bioinformatics. We searched the miRNA databases: Target scan (http://www.targetscan.org/) for miR-185 that target ROCK2, their sequences and their chromosome localization.

Luciferase assays. The WT-3'-UTR of ROCK2 or MUT-3'-UTR of ROCK2 was inserted into the pGL3 promoter vector (GenScript Co., Ltd., Nanjing, China) for luciferase reporter experiments. Then, the vector and miR-185-5p mimic were transfected into SNU-387 cells by Lipofectamine 2000 (Invitrogen; Thermo Fisher Scientific, Inc.). The cells were cultured in a 24-well plate. About $48 \mathrm{~h}$ after transfection, the Dual-Luciferase ${ }^{\circledR}$ Reporter Assay System (Promega Corp., Madison, WI, USA) was applied to perform luciferase assays.

Transwell migration and invasion assay. A total of $5 \times 10^{4} \mathrm{HCC}$ cells without serum were put in the upper chamber on the non-coated membrane, and the lower chamber was filled with $20 \%$ FBS to induce HCC cells to migrate or invade through the membrane. The cells were put in the upper chamber with the coated membrane for invasion assay. Then the cells were
Table I. Relationship between miR-185-5p expression and their clinicopathological characteristics in 54 patients with $\mathrm{HCC}$.

\begin{tabular}{|c|c|c|c|}
\hline \multirow[b]{2}{*}{ Characteristics } & \multicolumn{2}{|c|}{$\operatorname{miR}-185-5 p$} & \multirow[b]{2}{*}{ P-value } \\
\hline & Low & High & \\
\hline Age (years) & & & 0.424 \\
\hline$\geq 60$ & 16 & 13 & \\
\hline$<60$ & 13 & 12 & \\
\hline Sex & & & 0.221 \\
\hline Male & 16 & 14 & \\
\hline Female & 13 & 11 & \\
\hline $\mathrm{AFP}(\mathrm{ng} / \mathrm{ml})$ & & & 0.077 \\
\hline$\leq 20$ & 12 & 10 & \\
\hline$>20$ & 17 & 15 & \\
\hline Tumor size $(\mathrm{cm})$ & & & 0.151 \\
\hline$\geq 5$ & 17 & 11 & \\
\hline$<5$ & 12 & 14 & \\
\hline Liver cirrhosis & & & 0.150 \\
\hline None & 11 & 12 & \\
\hline Yes & 18 & 13 & \\
\hline TNM stage & & & 0.095 \\
\hline $\mathrm{I}+\mathrm{II}$ & 15 & 16 & \\
\hline $\mathrm{III}+\mathrm{IV}$ & 14 & 9 & \\
\hline Tumor stage & & & $0.002^{\mathrm{a}}$ \\
\hline $\mathrm{I}+\mathrm{II}$ & 20 & 14 & \\
\hline III & 9 & 11 & \\
\hline Lymph node metastasis & & & $0.016^{\mathrm{a}}$ \\
\hline None & 10 & 10 & \\
\hline Yes & 19 & 15 & \\
\hline
\end{tabular}

Statistical analyses were performed by the $\chi^{2}$ test. ${ }^{\text {a }} \mathrm{P}<0.05$ was considered significant. HCC, hepatocellular carcinoma.

incubated for $48 \mathrm{~h}$ to detect cell migration and invasion. Cells on the lower surface of the membrane were fixed with $4 \%$ paraformaldehyde, stained with $1 \%$ crystal violet for $5 \mathrm{~min}$ and subsequently counted in 3 randomly selected fields under 
A

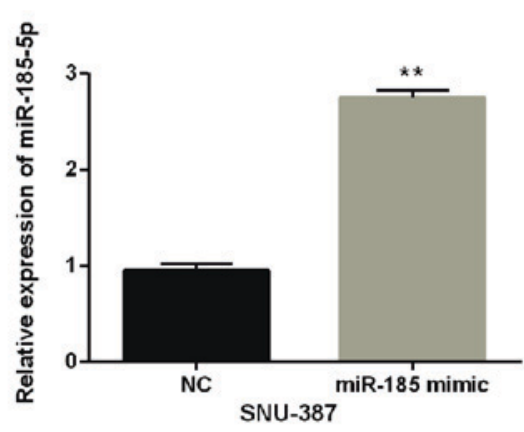

C

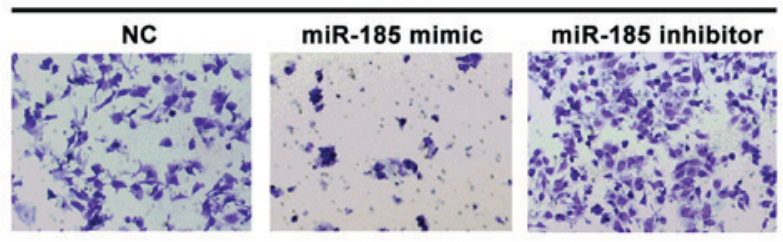

D

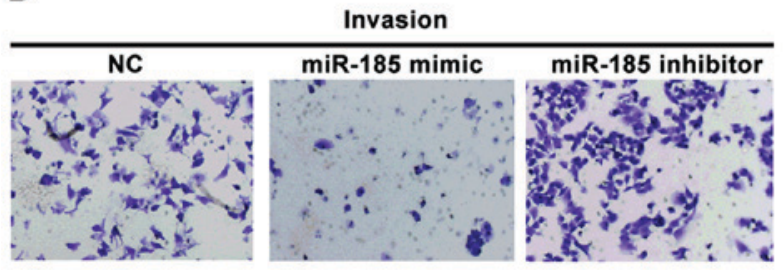

B
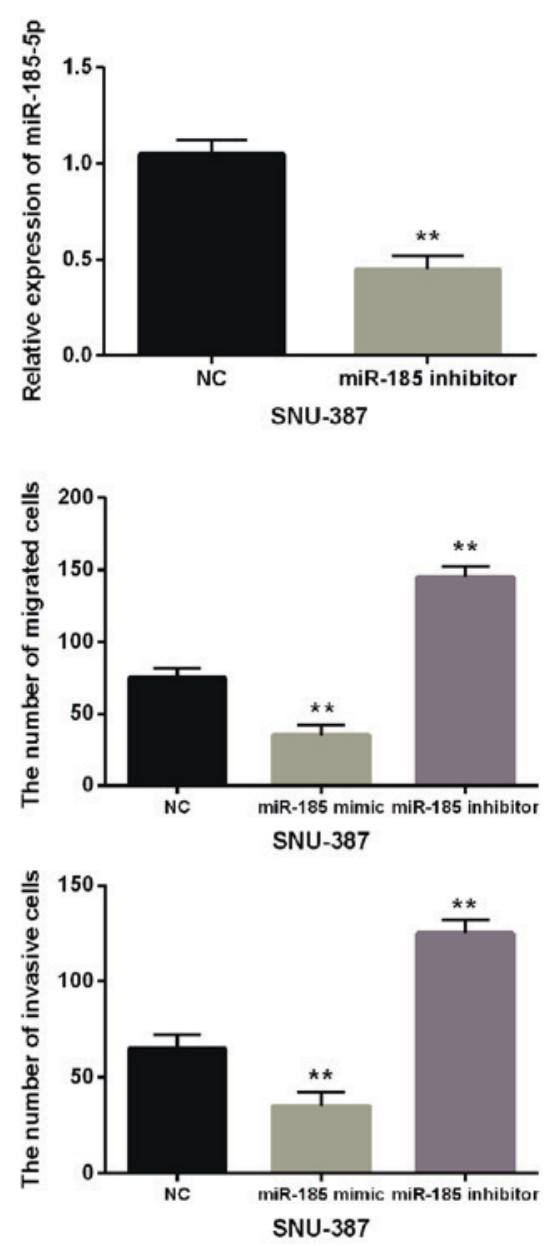

Figure 2. miR-185-5p overexpression inhibits cell migration and invasion in HCC. (A and B) miR-185-5p mimic or inhibitor was transfected into SNU-387 cells, and miR-185-5p level was detected via RT-qPCR. (C) Overexpression of miR-185-5p significantly decreased migratory and invasive abilities in SNU-387 cells. (D) miR-185-5p expression inhibitor increased migratory and invasive abilities in SNU-387 cells. ${ }^{* *} \mathrm{P}<0.01$. HCC, hepatocellular carcinoma; RT-qPCR, reverse transcription-quantitative PCR.

an inverted microscope (Leica Microsystems GmbH, Wetzlar, Germany) at magnification x200.

Western blotting. The protein samples were obtained using RIPA buffer. Protein concentration was calculated using bicinchoninic acid (BCA). Equal amounts of protein (30 $\mu \mathrm{g})$ were separated through 10\% SDS-PAGE and then incubated with $5 \%$ skim milk blocked membranes at room temperature. Next we incubated the membranes overnight at $4^{\circ} \mathrm{C}$ with anti-ROCK2 (rabbit polyclonal; dilution, 1:1,000; cat. no. ab71598; Abcam, Shanghai, China), anti-GAPDH antibodies (rabbit monoclonal; dilution, 1:1,000; cat. no. ab181602; Abcam) and subsequently incubated with matched goat anti-rabbit G-horseradish peroxidase secondary antibody (dilution, 1:2,000; cat. no. sc-2054; Santa Cruz Biotechnology Inc., Dallas, TX, USA). Then, protein expression levels were measured by ECL.

Statistical analysis. Statistical and diagram analyses used GraphPad Prism 6.0 and SPSS 17.0 software (SPSS, Inc., Chicago, IL, USA). Data are presented as the mean \pm SD. The difference was analyzed by Chi-square test or one-way ANOVA using the Tukey's post hoc test. Differences were considered significant at $\mathrm{P}<0.05$.

\section{Results}

miR-185-5p levels are decreased in HCC. To explore the change of miR-185-5p in HCC, we conducted RT-qPCR in HCC tissues and cell lines (Hep-3B, SNU-387 and LO-2). Expression of miR-185-5p was obviously downregulated in HCC tissues (Fig. 1A). miR-185-5p levels were lower in Hep-3B and SNU-387 than the normal LO-2 cell line (Fig. 1B). Furthermore, the correlation between clinical characteristics and miR-185-5p level was calculated in 54 HCC tissues. We found that a low expression of miR-185-5p was associated with tumor grade and lymph node metastasis $(\mathrm{P}<0.05)$. There was no association among miR-185-5p expression and other clinical characteristics (Table I, P>0.05).

miR-185-5p overexpression inhibits cell migration and invasion in HCC. To confirm the effect of miR-185-5p on the metastasis of HCC, miR-185-5p mimic or inhibitor was transfected into SNU-387 cells (Fig. 2A and B). Functionally, miR-185-5p overexpression obviously suppressed migration and invasion of SNU-387 cells (Fig. 2C). Downregulation of miR-185-5p significantly promoted cell metastasis of SNU-387 cells (Fig. 2D). Thus, we speculated that the effect of miR-185-5p on cell metastasis in HCC was dependent on its altered expression. 
A

\begin{tabular}{|c|c|}
\hline & $\begin{array}{l}\text { Predicted consequential pairing of target region (top) } \\
\text { and miRNA (bottom) }\end{array}$ \\
\hline $\begin{array}{l}\text { osition 2458-24 } \\
\text { sa-miR-185-5p }\end{array}$ & $\begin{array}{c}5^{\prime} \text {... AGGGUGAAAAAAAAAUCUCUCCC. .. } \\
\text { IIIIIIII } \\
3^{\prime} \quad \text { AGUCCUUGACGGAAAGAGAGGU }\end{array}$ \\
\hline
\end{tabular}

B

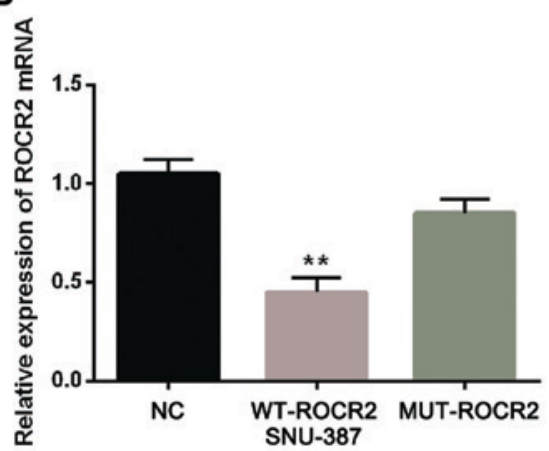

C

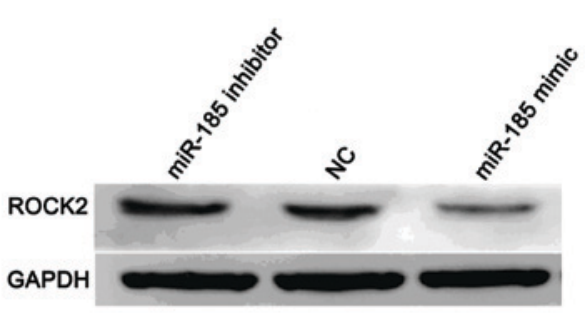

Figure 3. miR-185-5p directly targets ROCK2. (A) The binding sites of wild-type of ROCK2 3'-UTR combined with miR-185-5p. (B) Luciferase reporter assay. (C) The protein expression of ROCK2 was analyzed in cells transfected with miR-185-5p mimic or inhibitor. ${ }^{* *} \mathrm{P}<0.01$. ROCK2, Rho-associated coiled-coil containing protein kinase 2 .

A

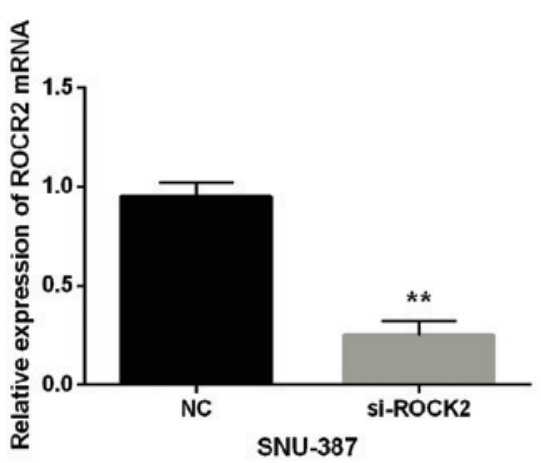

C

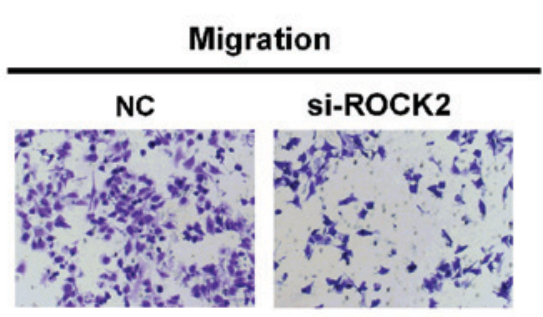

D

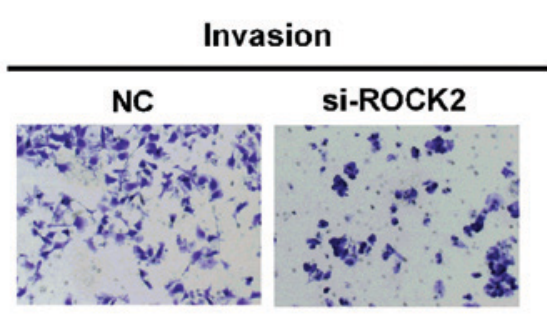

B
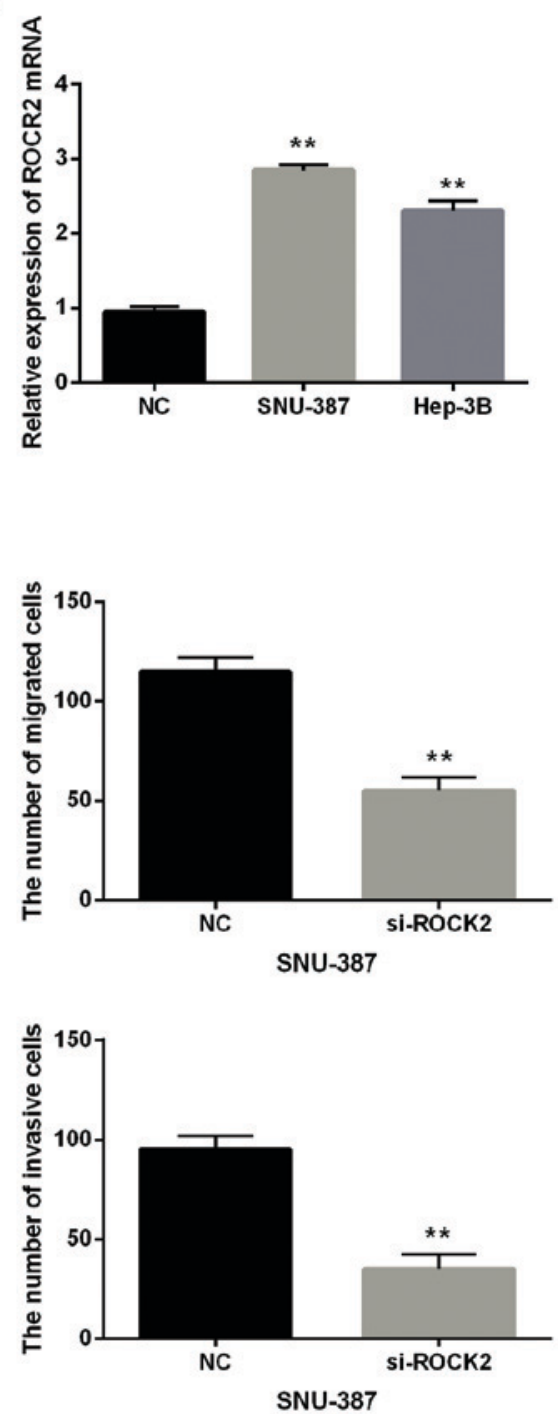

Figure 4. ROCK2 silence inhibits migration and invasion in HCC. (A) The ROCK2 expression in cells containing si-ROCK2 was confirmed via RT-qPCR. (B) The ROCK2 expressions in Hep-3B, SNU-387 and LO-2 (control) were detected by RT-qPCR. (C and D) The Transwell assays in SNU-387 cells containing si-ROCK2. ${ }^{* *} \mathrm{P}<0.01$. HCC, hepatocellular carcinoma; ROCK2, Rho-associated coiled-coil containing protein kinase 2; RT-qPCR, reverse transcription-quantitative PCR. 
A

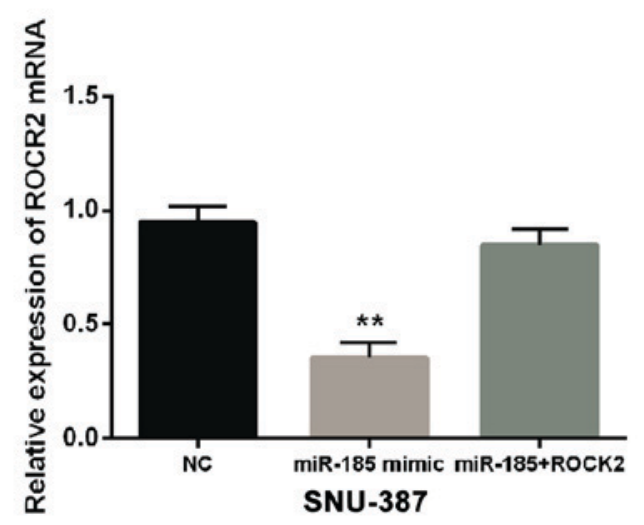

B
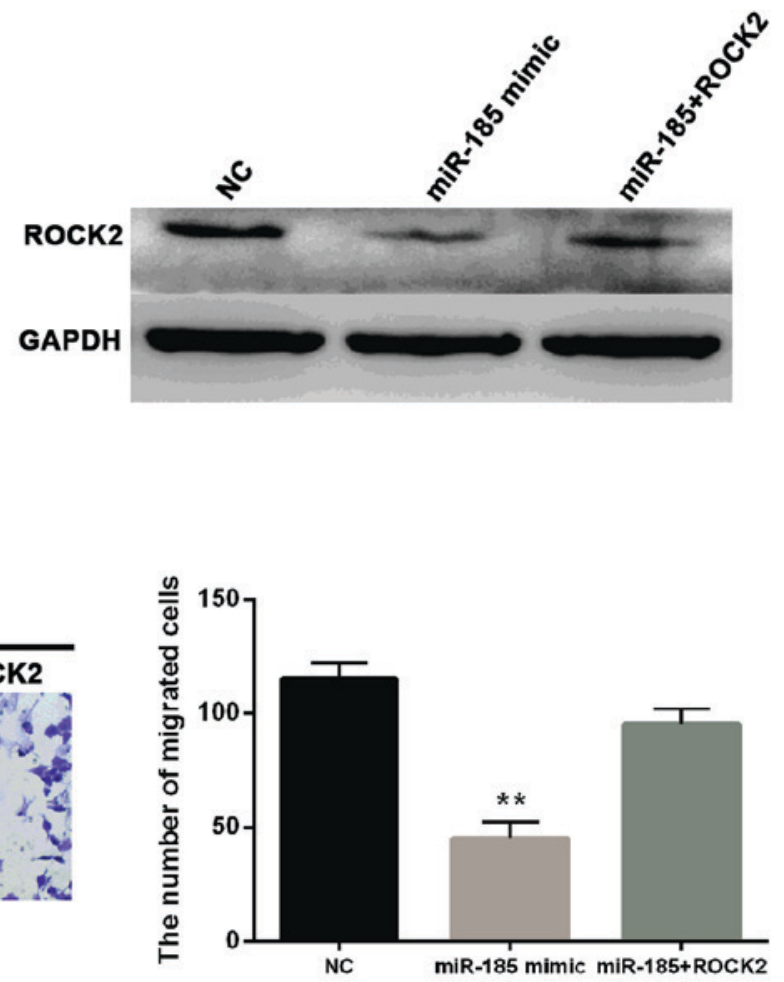

SNU-387

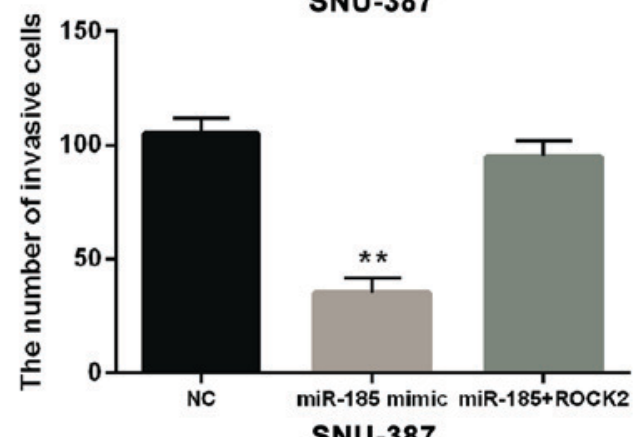

Figure 5. miR-185-5p regulates cell metastasis of HCC by suppressing ROCK2. (A) The relative mRNA expression of ROCK2 in the miR-185-stably-overexpressing SNU-387 cells treated for ROCK2. (B) The protein expression in cells contained miR-185-5p and ROCK2. (C and D) The Transwell assays for migration and invasion were performed in cells containing miR-185-5p mimic and ROCK2. ${ }^{* * *} \mathrm{P}<0.01$. HCC, hepatocellular carcinoma; ROCK2, Rho-associated coiled-coil containing protein kinase 2 .

miR-185-5p directly targeted ROCK2. Furthermore, we searched the target genes of miR-185-5p from TargetScan database (http://www.targetscan.org/vert_71/) to investigate its downstream regulation mechanism in $\mathrm{HCC}$ and it predicted the binding site of ROCK2 for miR-185-5p (Fig. 3A). Next, we confirmed the above prediction through luciferase reporter assay. The miR-185-5p mimic and WT-ROCK2 or MUT-ROCK2 plasmid were co-transfected into SNU-387 cells. Moreover, the luciferase activities were obviously decreased in group with miR-185-5p mimic and WT-ROCK2 while there was almost no change in group with miR-185-5p mimic and MUT-ROCK2 (Fig. 3B). In addition, miR-185-5p effect on ROCK2 expression at protein level was detected in SNU-387 cells with miR-185-5p mimic or inhibitor. ROCK2 protein levels were enhanced by miR-185-5p inhibitor but decreased by miR-185-5p mimic (Fig. 3C). Therefore, miR-185-5p directly targeted ROCK 2 and was negatively associated with ROCK 2 expression.
ROCK2 silence inhibits migration and invasion in HCC. In addition, si-ROCK2 was synthesized and transfected into SNU-387 cells to investigate ROCK2 in HCC. The transfection efficiency was assessed by RT-qPCR (Fig. 4A). ROCK2 mRNA expression in HCC cell lines was also detected. The upregulation of ROCK2 was identified in Hep-3B and SNU-387 in comparison with the normal LO-2 cell line (Fig. 4B). Moreover, the Transwell assay was applied to analyze cell metastasis of HCC. ROCK2 silence was observed to inhibit cell migration and invasion in HCC (Fig. 4C and D). Thus, we inferred that ROCK 2 would play an oncogenic role in HCC development.

miR-185-5p regulates cell metastasis of HCC through suppressing ROCK2. Based on the above results, miR-185-5p was considered to repress the effect of ROCK2. For confirmation miR-185-5p mimic was transfected into SNU-387 cells with negative control or ROCK 2 expression vector. The 
miR-185-5p reduced the ROCK2 levels at the mRNA and protein expression (Fig. 5A and B). Additionally, miR-185-5p impaired the effect of ROCK2 on promoting cell metastasis in SNU-387 cell lines (Fig. 5C and D). A series of evidence verified that miR-185-5p suppressed cell migration and invasion in HCC through suppression of ROCK2. These results may have the potential to affect tumorigenesis of HCC.

\section{Discussion}

The downregulation and inhibitory effect of miR-185-5p in HCC were identified by us and upregulation and promoted effect of ROCK2 were detected in HCC. Moreover, miR-185-5p was confirmed to directly target ROCK2 in HCC. These results might help us better understand the regulatory mechanism of HCC progression.

Previous studies demonstrated that miR-185 function varied from cancer to cancer. For instance, miR-185 as an oncogenic miRNA was found upregulated in gastric and bladder cancers according to miRNA profiling $(20,21)$. On the other hand, miR-185 expression was low and suppressed colorectal cancer cell proliferation and invasion (22). Similarly, Zhu et al reported that miR-185 level was decreased in HCC (23). Not surprisingly, we also detected downregulation of miR-185-5p in HCC which could be used as a biomarker for diagnosing HCC. Zhi et al also reported that miR-185 was a potential prognostic biomarker for HCC in early stage (24). Functionally, miR-185-5p has been confirmed to inhibit cell proliferation, tumor growth and EMT by regulating Six1, Six 2 and DNMT1/PTEN/Akt Pathway in HCC $(11,23,25)$. However, scarce research has been performed to explore the effect of miR-185 on cell metastasis in HCC. Thus, we detected the exact function of miR-185-5p for cell migration and invasion and proved that miR-185-5p had suppressive effect on cell metastasis in HCC.

To the best of our knowledge, the relationship between miR-185-5p and ROCK2 has not been investigated in human cancers. However, we proved that miR-185-5p directly targeted ROCK 2 in the current investigation. ROCK2 was reported to be overexpressed in HCC and to promote cell invasion through depredating MMP2 (26). Consistently, ROCK2 in HCC was also upregulated in our study. Moreover, ROCK2 was identified to influence cell metastasis and aggressiveness which was regulated by miR-124 and miR-139 in HCC $(27,28)$. In this study, ROCK2 was negatively associated with miR-185-5p and promoted HCC cell migration and invasion. Thus, we considered that miR-185-5p would impede cell migration and invasion by directly repressing ROCK2. However, we still need to explore whether miR-185-5p/ROCK2 regulates HCC progression through specific signaling pathways.

Collectively, miR-185-5p function as anti-metastatic miRNA was identified to be downregulated in HCC, and miR-185-5p upregulation repressed migration and invasion of HCC cells. Moreover, miR-185-5p directly targeted ROCK 2 and had negative correlation with its expression. ROCK 2 promoted cell metastasis in HCC. Therefore, miR-185-5p inhibited cell metastasis of HCC by suppressing ROCK2.

\section{Acknowledgements}

Not applicable.

\section{Funding}

Not applicable.

\section{Availability of data and materials}

The datasets used and/or analyzed during the present study are available from the corresponding author on reasonable request.

\section{Authors' contributions}

YN contributed to the conception of the study and wrote the manuscript. GT performed the data analyses. Both authors read and approved the final manuscript.

\section{Ethics approval and consent to participate}

The study was approved by the Ethics Committee of Linyi Central Hospital (Linyi, China). Signed informed consents were obtained from the patients or guardians.

\section{Patient consent for publication}

Not applicable.

\section{Competing interests}

The authors declare that they have no competing interests.

\section{References}

1. Llovet JM, Zucman-Rossi J, Pikarsky E, Sangro B, Schwartz M, Sherman M and Gores G: Hepatocellular carcinoma. Nat Rev Dis Primers 2: 16018, 2016.

2. Farazi PA and DePinho RA: Hepatocellular carcinoma pathogenesis: From genes to environment. Nat Rev Cancer 6: 674-687, 2006.

3. Kinoshita A, Onoda H, Fushiya N, Koike K, Nishino H and Tajiri H: Staging systems for hepatocellular carcinoma: Current status and future perspectives. World J Hepatol 7: 406-424, 2015.

4. Allen MD, Luong P, Hudson C, Leyton J, Delage B, Ghazaly E, Cutts R, Yuan M, Syed N, Lo Nigro C, et al: Prognostic and therapeutic impact of argininosuccinate synthetase 1 control in bladder cancer as monitored longitudinally by PET imaging. Cancer Res 74: 896-907, 2014.

5. Bartel DP: MicroRNAs: Genomics, biogenesis, mechanism, and function. Cell 116: 281-297, 2004.

6. Zhu H, Zhou X, Ma C, Chang H, Li H, Liu F and Lu J: Low expression of miR-448 induces EMT and promotes invasion by regulating ROCK2 in hepatocellular carcinoma. Cell Physiol Biochem 36: 487-498, 2015.

7. Chen W, Ye L, Wen D and Chen F: MiR-490-5p inhibits hepatocellular carcinoma cell proliferation, migration and invasion by directly regulating ROBO1. Pathol Oncol Res 2: 1-9, 2017.

8. Li Z and Wang Y: MiR-96 targets SOX6 and promotes proliferation, migration and invasion of hepatocellular carcinoma. Biochem Cell Biol bcb-2017-0183, 2017.

9. Jiang D, Cho W, Li Z, Xu X, Qu Y, Jiang Z, Guo L and Xu G: MiR-758-3p suppresses proliferation, migration and invasion of hepatocellular carcinoma cells via targeting MDM2 and mTOR. Biomed Pharmacother 96: 535-544, 2017.

10. Li X, Song H, Liu Z and Bi Y: miR-1260b promotes cell migration and invasion of hepatocellular carcinoma by targeting the regulator of G-protein signaling 22. Biotechnol Lett 40: 57-62, 2018. 
11. Imam JS, Buddavarapu K, Lee-Chang JS, Ganapathy S, Camosy C, Chen Y and Rao MK: MicroRNA-185 suppresses tumor growth and progression by targeting the Six 1 oncogene in human cancers. Oncogene 29: 4971-4979, 2010.

12. Takahashi Y, Forrest ARR, Maeno E, Hashimoto T, Daub CO and Yasuda J: MiR-107 and MiR-185 can induce cell cycle arrest in human non small cell lung cancer cell lines. PLoS One 4: e6677, 2009

13. Tang H, Wang Z, Liu X, Liu Q, Xu G, Li G and Wu M: LRRC4 inhibits glioma cell growth and invasion through a miR-185-dependent pathway. Curr Cancer Drug Targets 12: 1032-1042, 2012.

14. Akçakaya P, Ekelund S, Kolosenko I, Caramuta S, Ozata DM, Xie H, Lindforss U, Olivecrona $\mathrm{H}$ and Lui WO: miR-185 and miR-133b deregulation is associated with overall survival and metastasis in colorectal cancer. Int J Oncol 39: 311-318, 2011.

15. Kalender ME, Demiryürek S, Oztuzcu S, Kizilyer A, Demiryürek AT, Sevinc A, Dikilitas M, Yildiz R and Camci C: Association between the Thr431Asn polymorphism of the ROCK 2 gene and risk of developing metastases of breast cancer. Oncol Res 18: 583-591, 2010.

16. Vigil D, Kim TY, Plachco A, Garton AJ, Castaldo L, Pachter JA, Dong H, Chen X, Tokar B, Campbell SL, et al: ROCK1 and ROCK 2 are required for non-small cell lung cancer anchorage-independent growth and invasion. Cancer Res 72 : 5338-5347, 2012.

17. Ma W, Sze KM, Chan LK, Lee JM, Wei LL, Wong CM, Lee TK, Wong $\mathrm{CC}$ and $\mathrm{Ng} \mathrm{IO}$ : RhoE/ROCK2 regulates chemoresistance through NF- $\kappa$ B/IL-6/ STAT3 signaling in hepatocellular carcinoma. Oncotarget 7: 41445-41459, 2016.

18. Li M, Zhou W, Yuan R, Chen L, Liu T, Huang D, Hao L, Xie Y and Shao J: ROCK 2 promotes HCC proliferation by CEBPD inhibition through phospho-GSK $3 \beta / \beta$-catenin signaling. FEBS Lett 589: 1018-1025, 2015.

19. Livak KJ and Schmittgen TD: Analysis of relative gene expression data using real-time quantitative PCR and the 2(-Delta Delta C(T)) method. Methods 25: 402-408, 2001.

20. Yao Y, Suo AL, Li ZF, Liu LY, Tian T, Ni L, Zhang WG, Nan KJ, Song TS and Huang C: MicroRNA profiling of human gastric cancer. Mol Med Rep 2: 963-970, 2009.
21. Gottardo F, Liu CG, Ferracin M, Calin GA, Fassan M, Bassi P, Sevignani C, Byrne D, Negrini M, Pagano F, et al: MicroRNA profiling in kidney and bladder cancers. Urol Oncol 25: 387-392, 2007.

22. Liu M, Lang N, Chen X, Tang Q, Liu S, Huang J, Zheng Y and Bi F: miR-185 targets RhoA and Cdc42 expression and inhibits the proliferation potential of human colorectal cells. Cancer Lett 301: 151-160, 2011

23. Zhu SM, Chen CM, Jiang ZY, Yuan B, Ji M, Wu FH and Jin J: MicroRNA-185 inhibits cell proliferation and epithelial-mesenchymal transition in hepatocellular carcinoma by targeting Six2. Eur Rev Med Pharmacol Sci 20: 1712-1719, 2016.

24. Zhi Q, Zhu J, Guo X, He S, Xue X, Zhou J, Hu B, Li H, Chen S, Zhao H, et al: Metastasis-related miR-185 is a potential prognostic biomarker for hepatocellular carcinoma in early stage. Biomed Pharmacother 67: 393-398, 2013.

25. Qadir XV, Han C, Lu D, Zhang J and Wu T: miR-185 inhibits hepatocellular carcinoma growth by targeting the DNMT1/PTEN/Akt pathway. Am J Pathol 184: 2355-2364, 2014.

26. Huang D, Du X, Yuan R, Chen L, Liu T, Wen C, Huang M, Li M, Hao L and Shao J: Rock2 promotes the invasion and metastasis of hepatocellular carcinoma by modifying MMP2 ubiquitination and degradation. Biochem Biophys Res Commun 453: 49-56, 2014.

27. Zheng F, Liao YJ, Cai MY, Liu YH, Liu TH, Chen SP, Bian XW, Guan XY, Lin MC, Zeng YX, et al: The putative tumour suppressor microRNA-124 modulates hepatocellular carcinoma cell aggressiveness by repressing ROCK2 and EZH2. Gut 61: 278-289, 2012

28. Wong CC, Wong CM, Tung EK, Au SL, Lee JM, Poon RT, Man K and Ng IO: The microRNA miR-139 suppresses metastasis and progression of hepatocellular carcinoma by down-regulating Rho-kinase 2. Gastroenterology 140: 322-331, 2011.

(i) (9) This work is licensed under a Creative Commons Attribution-NonCommercial-NoDerivatives 4.0 International (CC BY-NC-ND 4.0) License. 